\title{
Effects of aircraft on aerosol abundance in the upper troposphere
}

\author{
G.V.Ferry', R.F.Pueschel' ${ }^{\text {'s }, A . W . S t r a w a ', ~ S . D . H o w a r d ~}{ }^{2}$, S.Verma ${ }^{3}$, M.J.Mahoney ${ }^{4}$, T.P.Bui', \\ J.R.Hannan', H.E.Fuelberg'.
}

\begin{abstract}
A significant increase in sulfuric acid aerosol concentration was detected above $10 \mathrm{~km}$ pressure altitude during cross-corridor flight out of Shannon on October 23, 1997. The source of this aerosol is ascribed to commercial aircraft operations in flight corridors above $10 \mathrm{~km}$, because (1) a stable atmosphere prevented vertical air mass exchanges and thus eliminated surface sources, (2) air mass back trajectories documented the absence of remote continental sources, and (3) temperature profiler data showed the tropopause at least one kilometers above flight aititude throughout the flight. Particle volatility identified $70 \% \mathrm{H}_{2} \mathrm{SO}_{4}, 20 \%\left(\mathrm{NH}_{4}\right)_{2} \mathrm{SO}_{4}$ and $10 \%$ nonvolatile aerosol in the proximity of flight corridors, and (10$30) \% \mathrm{H}_{2} \mathrm{SO}_{4}$, up to $50 \%\left(\mathrm{NH}_{4}\right)_{2} \mathrm{SO}_{4}$, and $(40-60) \%$ nonvolatile aerosols in air that was not affected by aircraft operations below $10 \mathrm{~km}$. Only a very small fraction of the non-volatile particles determined with a condensation nucleus counter) could be morphologically identified as soot aerosol (validated by scanning electron microscopy of wire impactor samples). The newly formed $\mathrm{H}_{2} \mathrm{SO}_{4}$ particles did not measurably affect surface area and volume of the background aerosol due to their small size, hence did not affect radiative transfer directly.
\end{abstract}

\section{Introduction}

Aircraft jet engines directly emit aerosols and condensable gases, such as water vapor $\left(\mathrm{H}_{2} \mathrm{O}\right)$ and sulfur dioxide $\left(\mathrm{SO}_{2}\right)$ which lead to the formation of new liquid (volatile) sulfuric acid $\left(\mathrm{H}_{2} \mathrm{SO}_{4}\right)$, particles in the carly plume by gas-to-particle conversion (nucleation) processes. Soot aerosol formed during incomplete fuel combustion constitute part of the nonvolatile particle fraction. The newly formed particles grow by condensation and coagulation amongst themselves and with the background aerosol.

\footnotetext{
NASA Ames Research Center, Moffett Field, CA

\$ Author to whom correspondence should be addressed

${ }^{2}$ Symtech Corporation, Arlington, VA

${ }^{3}$ Science and Technology Corporation, Lantham, MD

4 Jet Propulsion Laboratory, Pasadena, CA

$\checkmark$ Florida State University, Tallahassee, FL
} 
The differences between results from the log-normal curve lits and those derived by numerical integration lie within experimental error. Both data sets show that particle cuncentration is the only serosol characteristic that is significantly enhanced in air masses that are affected by aircraft operations, whereas surface area and volume densities are not. Fig. 3 indicates that those aircratt-produced particles are smaller than $0.1 \mu \mathrm{m}$ diameter. A comparison of the results of Fig.4 with those of Fig. 3 suggests that the majority of those particles are smaller than $0.05 \mu \mathrm{m}$. It is this small size that renders aircraftgenerated sulfuric acic particles unimportant for either aerosol surface area or volume. Their coagulation with other aerosols, however, may affect the surface characteristics of those aerosol particles by (partially) coating them with sulfuric acid. Thus it is possible that particles that are initially hydrophobic, such as sooh are converted to effective cloud condensation nuclei to potentially affect the cloud particle sizes and concentrations and thus cause indirect effects.

The Ames Wire Impactor sampies were also analyzed for soot aerosol which is identified morphologically by the fractal nature of soot particles. thereby distinguishing them uniquely from other aerosols (e.g., Pueschel et al., 1992, 1999). Those results are also shown in Table 2. From this data it follows that, in contrast to a significant effect on the sulfuric acid fine-particle abundance, aircraft leave no measurable imprint on the soot aerosol characteristics. Of particular note is the fact that the morphologically determined soot aerosol comprises a mere few percent of the total aerosol. in contrast, the non-volatile aerosol iraction identified by preheating air prior to entering a $\mathrm{CN}$ counter (Fig. 1 and Table 1) amounts to up to $13 \%$. In order to resolve this discrepancy, one has to assume that either $\mathrm{CN}$ counters detect refractory aerosols other than soot, including only partially evaporated $\left(\mathrm{NH}_{4}\right)_{2} \mathrm{SO}_{4}$ and/or chemions, or that the majority of soot particles are too small $(<0.05 \mu \mathrm{m})$ to efficiently be collected by inertial impingement on wire impactors. The latter assumption is doubtful, because electron-microscopic analysis of soot fractals shows that individual soot spherules are large enough to be collected by wire impactors.

\section{Summary}

A sub-adiabatic lapse rate, amplified by several inversion layers at various altitudes, prevented vertical exchange of air masses during a cross-corridor flight out of Shannon on 23 October 1997. Air mass back trajectories showed that air parcels reaching the aircraft had been over the Atlantic Ocean for at least 5 days prior to sampling. In spite of this inhibited vertical and horizontal transport, a drastic up to tenfold enhancement of fine particle concentration was detected above $10 \mathrm{~km}$ pressure altitude in relation to concentrations at lower altitudes. Thus aircraft operated in flight corridors above $10 \mathrm{~km}$ were the most likely source of this fine-particle abundance.

Volatility measurements identified sulfuric acid as the compound of the aircraft-generated aerosol, raising the sulfuric acid fraction of the total aerosol to $>70 \%$. The rest was equally divided between $\left(\mathrm{NH}_{4}\right)_{2} \mathrm{SO}_{4}$ and a non-volatile component, a small fraction of which was soot aerosol. In contrast, sulfuric acid 
shown in boch the MMMS and DCTP Jata, separated air masses sbuve $10 \mathrm{~km}$ trom those below that altitude.

The Florida State University (FSU) air mass back trajectory model showed the confinement of air masses vithin 25 degrees latitude over the Atlantic Ocean upwind of the flight track both above and below $10 \mathrm{~km}$ pressure altitude for $S$ days prior to 23 October. This absence of long-range transport prevented advection of pollutants from North America and permitted accumulation of aircraft emissions in the proximity of corridors upwind of the sampling aircraft.

The inhibited transport of zerosols from both the Atlantic Ocean's boundary layer and the North American continent left aircrat lying in corridors above $10 \mathrm{~km}$ as the most likely source of particulate pollutants along the flight track.

Figure 1 shows in the upper panel the ambient fine particle

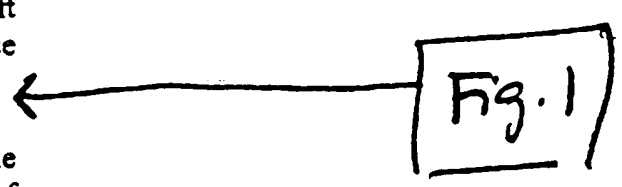
(CN) concentration, and in the lower panel the fraction of particles that remain at $120 \mathrm{C}, 200 \mathrm{C}$, and $300 \mathrm{C}$, respectively, for all of the flight as function of UTC time. CN particles were detected by growing particles $>0.01 \mu \mathrm{m}$ at $400 \%$ supersaturation in the cloud chamber of a TSI Model $2000 \mathrm{CN}$ counter to optically detectable sizes. A heater upstream of the $\mathrm{CN}$ counter permitted differential heating of the air up to $300 \mathrm{C}$ prior to entering the cloud chamber. Noticeable in Fig. 1 is a significant increase in fine particle abundance at $28,800 \mathrm{sec}$ UTC when the aircraft ascended through $10 \mathrm{~km}$ pressure altitude, and a corresponding decrease at $40,050 \mathrm{sec}$ UTC while passing through $10 \mathrm{~km}$ pressure altitude during descent. This change in fine particle concentration stands out in spite of fairly large fluctuations in fine-particle abundance at any altitude. Simultaneous gas measurements by other investigators yielded $\approx 40$ ppbv $\mathrm{O}_{3}$ and $60-70 \mathrm{ppbv} \mathrm{CO}$, both indicative of tropospheric air. While both $\mathrm{O}_{3}$ and $\mathrm{CO}$ were fairly constant throughout the flight, NOy was enhanced above $10 \mathrm{~km}$ proportional to the increase in CN. The simultaneous existence at $10 \mathrm{~km}$ of a temperature inversion supports the assumption that the elevated fine-particle concentration above $10 \mathrm{~km}$ pressure altitude is related to aircraft operations in flight corridors above FL330.

Figure 2 shows the fraction of particles remaining at $120 \mathrm{C}$,

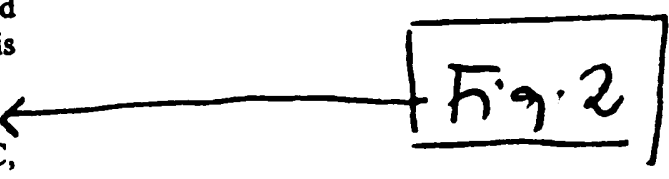
$200 \mathrm{C}$ and $300 \mathrm{C}$ temperatures in relation to the thermal volatility spectra (Clarke, 1991) of $\mathrm{H}_{2} \mathrm{SO}_{4}$ (curve dropping off near 120C) and $\left(\mathrm{NH}_{4}\right)_{2} \mathrm{SO}_{4}$ (curve dropping off near $240 \mathrm{C}$ ). Table 1 summarizes those results.

Table 1: Concentration and thermal characteristics of $C N$ below and above $10 \mathrm{~km}$ pressure altitude $Z$.

\begin{tabular}{lcccccccc}
\hline$Z(\mathrm{~km})$ & \multicolumn{5}{c}{$\leq 10 \mathrm{~km}$} & & \multicolumn{3}{c}{$>10 \mathrm{~km}$} & \\
$\mathrm{~T}\left({ }^{\circ} \mathrm{C}\right)$ & Ambient & 120 & 200 & 300 & Ambient & 120 & 200 & 300 \\
$\mathrm{CN}\left(\mathrm{cm}^{-3}\right)$ & $792 \pm 255$ & $543 \pm 111$ & $392 \pm 81$ & $292 \pm 92$ & $1653 \pm 390$ & $444 \pm 120$ & $348 \pm 168$ & $243 \pm 143$ \\
$\%$ lost & 0 & $31 \pm 10$ & $50 \pm 19$ & $63 \pm 17$ & 0 & $73 \pm 10$ & $79 \pm 11$ & $86 \pm 9$
\end{tabular}

We see from Table 1 that the average ambient fine-particle abundance above $10 \mathrm{~km}$ pressure altitude was more than double the concentration below $10 \mathrm{~km}$. It follows further from Fig.2 and Table 1 that $73 \%$ by number of fine particles in the air mass above $10 \mathrm{~km}$ near commercial flight corridors consisted of sulfuric acid, while $14 \%$ could be classified as "non-volatile" aerosols (defined as those that exist at 300C) and 13\% showed 
thermal characteristics that were typical of $\left(\mathrm{NH}_{4}\right)_{2} \mathrm{SO}_{4}$. In contrast, below $10 \mathrm{~km}$, only $31 \%$ of the aerosol showed volatility that is rypical of sulfuric acid, $37 \%$ resembled nonvolatile serosols, and $32 \%$ were $\left(\mathrm{NH}_{4} / 2 \mathrm{SO}_{4}\right.$-like. Thus, the sulfuric acid derosol sbundance above $10 \mathrm{~km}$ was enhanced in proportion to total serosol enhancement in relation to concentrations below 10 $\mathrm{km}$. Therefore, the doubling of fine particle concentration above $10 \mathrm{~km}$ is due exclusively to sulfuric acid aerosol that has been emitted into that air mass by aircraft.

The aerosol characteristic that determines both heterogeneous reaction rates and light scattering properties is the particle surface area density. CN measurements alone do not permit a determination of particle surface area, because they constitute a bulk particle density without significant information on particle size. The only information about particle size that is available from $C N$ measurements is a detectable minimum size which depends on the supersaturation at which $\mathrm{CN}$ counters are being operated.

We determined particle number, surface area and volumes independently from $\mathrm{CN}$ measurements by collecting particles by impaction on wires. This sampling technique (e.g., Pueschel et al., 1992) by inertial impaction is fundamentally different from $\mathrm{CN}$ measurements. The collection efficiency of particles on wires at nominal jet aircraft speeds drops off rapidly at $0.05 \mu \mathrm{m}$ particle diameter (Lem and Farlow, 1979). But impactor sampling has a distinctive advantage over other techniques, however, by allowing morphological and chemical analysis of those particles that were collected, thereby offering the capability of a distinction between soot and other particles (Pueschel et al., 1992).

Figure 3 shows particle size distributions from samples 479.3 collected on 23 October below and above $10 \mathrm{~km}$ pressure altitude. Least square curve fits to the data yield log-normal characteristics $N_{01}=4.0 \mathrm{~cm}^{-3}, r_{01}=0.09 \mu \mathrm{m}$ and $\sigma_{1}=1.8$ for the lower, and $\mathrm{N}_{02}=40 \mathrm{~cm}^{.3}, \mathrm{r}_{02}=0.02 \mu \mathrm{m}$ and $\sigma_{2}=2.0$ for the higher altitude, respectively. From those log-normal parameters follow particle surface area densities $A_{1}=0.81 \mathrm{\mu m}^{2} \mathrm{~cm}^{-3}$ and $A_{2}=0.60$ $\mu \mathrm{m}^{2} \mathrm{~cm}^{-3}$ and particle volume densities $V_{1}=0.057 \mu^{3} \mathrm{~cm}^{-3}$ and

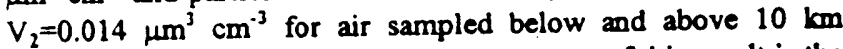
pressure altitude, respectively. The importance of this result is the fact that aircraft operations do not enhance either particle surface area or particle volume of particles larger than $0.05 \mu \mathrm{m}$ radius, in spite of a significant increase of fine-particle concentration.

Particle concentration, surface area and volume densities have been derived independently from log-normal curve fits by integrations over number (shown in Fig.3), surface area and volume size distributions. The results are shown in Table 2.

Table 2:Particle number, surface area and volume densities above and below $10 \mathrm{~km}$ pressure altitude.

\begin{tabular}{|c|c|c|c|c|}
\hline \multirow{2}{*}{$Z(\mathrm{~km})$} & \multicolumn{2}{|c|}{$\leq 10 \mathrm{~km}$} & \multicolumn{2}{|c|}{$\geq 10 \mathrm{~km}$} \\
\hline & Aerosol & Soot & Aerosol & Soot \\
\hline$N\left(\mathrm{~cm}^{-3}\right)$ & $4.6 \pm 0.3$ & $(1.9 \pm 1.0) e-1$ & $40 \pm 1.4$ & $(9.6 \pm 3.4)-2$ \\
\hline$A\left(\mu \mathrm{m}^{2} \mathrm{~cm}^{-3}\right)$ & $(7.7 \pm 0.9) \propto-1$ & $(3.7 \pm 1.9) \propto-2$ & $(6.0 \pm 0.9) 0-1$ & $(2.4 \pm 1.2) 0-2$ \\
\hline$V\left(\mu \mathrm{m}^{3} \mathrm{~cm}^{\cdot 3}\right)$ & $(4.8 \pm 0.9) e-2$ & $(2.3 \pm 1.1) e-4$ & $(1.6 \pm 0.8) e-2$ & $(1.9 \pm 0.9)=-4$ \\
\hline
\end{tabular}


Aviation-produced particles may influence the state of the atmosphere in various ways. For example, they provide surfaces for beterogeneous chemical reactions. Heterogeneous reaction rates depend on the chemical characteristics of aerosols. For example, the reaction probabilities of $\mathrm{N}_{2} \mathrm{O}_{3}$ on $\mathrm{NH}_{4} \mathrm{HSO}_{4}$, to which $\mathrm{H}_{2} \mathrm{SO}_{4}$ from aircraft could be reduced with ammonia from background air, show a strong dependence on relative humidity and temperature, decreasing with lowering relative humidity and increasing temperature (Mozurkewich and Calvert, 1988). In contrast, measurements of $\mathrm{N}_{2} \mathrm{O}$, hydrolysis on $\mathrm{H}_{2} \mathrm{SO}_{4}$ particles show only a weak dependence on temperature and relative humidity (Hanson and Ravishankara, 1991). Therefore, it is important to determine the enhancement of $\mathrm{H}_{2} \mathrm{SO}_{4}$ aerosol by aircraft in relation to the fraction of those particles that are neutralized to $\left(\mathrm{NH}_{4}\right)_{2} \mathrm{SO}_{4}$ in order to assess the atmospheric chemical modification potential of aircraft-produced aerosol. Aviation-generated aerosols also form a sink for condensable gases, they absorb or scatter radiation directly, and they change cloud properties which may affect radiation indirectly (IPCC; 1999). In order to assess those effects, aviation-produced aerosol characteristics have to be determined in relation to background aerosol properties.

Effects of aircraft on the sulfur and soot aerosol budgets are not at all clear. While Fahey et al. (1995a,b) found enhancements above background of both volatile and nonvolatile fine particles in the stratosphere, Dibb et al. (1998) were unable to confirm those findings for the upper troposphere. A stable atmosphere on 23 October 1997 separated air masses containing flight corridors above $10 \mathrm{~km}$ from air masses below $10 \mathrm{~km}$ that were not affected by air traffic. Temperature profiler data determined a height of the tropopause that was above DC- 8 flight levels by at least $1 \mathrm{~km}$ throughout the flight. Furthermore, air mass back trajectories established the absence of long range transport of pollutants from the North American continent. Thus, SONEX (Subsonic Assessment-Ozone Nitrogen Oxide Experiment) Flight No. 7 on that day provided an opportunity to determine aerosol characteristics in both aircraft-affected and non-affected air masses in the upper troposphere.

In this paper we document that subsonic aircraft emissions below the tropopause at northern mid-latitudes are a source of sulfuric acid aerosol. Even though an adiabatically stable atmosphere may be required to detect this pollutant, and even though the particles are too small to measurably affect surface area and volume densities, this finding is an affirmative answer to one of the key questions addressed by SONEX: Can aircraft corridors be detected?

\section{Results}

Both the Ames MMS (Meteorological Measuring System) and the Jet Propulsion Laboratory MTP (Microwave Temperature Profiler) established the existence of a sub-adiabatic lapse rate during a cross-corridor flight out of Shannon on 23 October 1997. MTP data show that the lapse rate varied between -6.5 and $-7.5^{\circ} \mathrm{C} / \mathrm{km}$ (against a $-9.9^{\circ} \mathrm{C} / \mathrm{km}$ dry adiabatic lapse rate) during the entire flight. This atmospheric stability prevented vertical air mass exchange. Furthermore, a slight temperature inversion, 
amounted to only $31 \%$ in the air mass below $10 \mathrm{~km}$ pressure altitude which was not affected by aircraft.

Ames wire impactor samples, collected concurrently with the tine particle measurements, showed that only particle number density was influenced by aircraft. Neither particle surface area nor volume densities were affected because of the small size $(<0.05 \mu \mathrm{m})$ of the aircraft-generated particles. Thus, a direct radiative effect of aircraft-produced aerosol is not to be expected. However, coagulation with the aircraft-generated sulfuric particles could render hydrophobic aerosols, such as soot, to become eloud condensation nuclei and thereby constitute an indirect $* f f e c t$.

From the impactor samples we could morphologically identify the fraction of the aerosol that was soot particles. Soot contributed only $4 \%$ and $0.2 \%$ by number, respectively, to the aerosol below and above $10 \mathrm{~km}$ pressure altitude. In contrast, the non-volatile particle fraction determined with a $\mathrm{CN}$ counter was as high as $37 \%$. In any case, in contrast to sulfuric acid fine particles, aircraft have no measurable effect on soot aerosol concentration. Soot particles, however, are subject to radiometric forces due to their bigh absorptivity of sunlight and asymmetric shape (Pueschel et al., 1999). As a consequence, their atmospheric residence time is longer than that of other aerosols and they can be transported against gravity up to 80 kilometers, where they might affect mesospheric physics.

There exists a discrepancy between a non-volatile aerosol component determined by $\mathrm{CN}$ counters and soot aerosol identified morphologically by impactor samples. To resolve this discrepancy one has to assume that either the $\mathrm{CN}$ counterdetermined non-volatile aerosol is composed of more refractory compounds than only soot, for example of only partially evaporated ammonium sulfate, sea salt or mineral particles, or that the majority of soot particles that are detected by $\mathrm{CN}$ counters are too small to be collected efficiently by wire impactors. Because the supersaturations in $\mathrm{CN}$ counters are extremely high, the possibility exists that they possibly count chemions which are generated in aircraft jet engines (Yu and Turco, 1997). We, therefore, caution against an unqualified interpretation of non-volatile CNs as soot particles.

Acknowledgments. We thank Duane Allen for engineering and operation of the airborne aerosol measurement system. The MTP work performed by M.J.Mahoney was carried out by the Jet Propulsion Laboratory, Califomia Institute of Technology, under a contract with NASA. The research was supported by NASA's Atmospheric Effects of Aircraft Assessment Program.

\section{References.}

Clarke, A.D., A thermo-optic technique for in situ analysis of sizeresolved aerosol physicochemistry, Atmos. Environ. 25A, 635-644, 1991.

Dibb, J. et al., Tropospheric sulfate distribution during SUCCESS: Contributions from jet exhaust and surface sources, Geophys. Res. Lett. 25. 1375, 1998. 
Fahey. DW. and 21 other authors, In situ observations in aircraft exhaust plumes in the lower stratosphere at mid latitudes, J.Geophys Res,. $100,3065-3074,1995$ a

Fahey, D.W, and 23 other co-authors, Emission measurements of the Concorde supersonic urcraft in the lower stratosphere, Sctence. 270. $70-74.19956$

Hanson. D.R., and A.R.Ravishankara. The reaction probabilities of CIONO2 and $\mathrm{N} 2 \mathrm{O} 5$ on $40-75 \%$ sulfuric acid solutions, J.Geophys. Res., 96, 17,307-17,314, 1991.

PCC (Intergovemmental Panel on Climate Change) Special Report: Effects of Aviation on the Atmosphere, Geneva, 1999.

Lem, H.Y, and V.H.Farlow, Efficiency of aerosol collection on wires exposed in the stratosphere, NASA Technical Memorandum 81147 , 1979.

Mozurkevich, M., and J.G.Calver, Reaction probability of N2OS on aqueous aerosol, J.Geophys.Res., 93, 15,889-15,896, 1988.

Pueschel, R.F., D.F. Blake, K G.Snetsinger, A.D.A.Hansen, S.Verma, and K.Kato, Black carbon (soot) aerosol in the lower stratosphere and upper troposphere, Geophys. Res.Lett. 19, 1659-1662, 1992.

Pueschel, R.F, S.Verma, H.Rohatschek, G.V.Ferry, N.Boiadijeva, S.D. Howard and A.W. Strawa. Transport of aircraft-produced soot into the middle atmosphere by gravito-photophoresis, J.Aerasol Sci. 1999 (submitted)

$Y u, F$, and R.P.Turco, The role of ions in the formation and evolution of particles in aircraft plumes, Geophys.Res.Lett., 24, 1927-1930, 1997.

Figure 1. Upper panel: Ambient $\mathrm{CN}$ particle concentration. Lower panel: Fractions of particles remaining at $120 \mathrm{C}$ (diamonds), 200C (triangles) and 300C (squares). Abscissa in both panels is flight time in UTC seconds. Date is 23 October 1997.

Figure 2. Thermal decomposition spectra of sulfuric acid (squares) and ammonium sulfate (circles). The diamonds and triangles are averages of measurements below $10 \mathrm{~km}$ and above $10 \mathrm{~km}$ pressure altitude, respectively on 23 October 1997.

Figure 3. Particle size distributions measured above $10 \mathrm{~km}$ at 8:59-9:01 UTC (open circles) and below $10 \mathrm{~km}$ at 7:09-7:12 UTC (solid circles) pressure altitudes on 23 October 1997.

Figure 1. Upper panel: Ambient CN particle concentration. Lower panel: Fractions of particles remaining at $120 \mathrm{C}$ (diamonds), 200C (triangles) and 300C (squares). Abscissa in both panels is flight time in UTC seconds. Date is 23 October 1997.

Figure 2. Thermal decomposition spectra of sulfuric acid (squares) and ammonium sulfate (circles). The diamonds and triangles are averages of measurements below $10 \mathrm{~km}$ and above $10 \mathrm{~km}$ pressure altitude, respectively on 23 October 1997.

Figure 3. Particle size distributions measured above $10 \mathrm{~km}$ at 8:59-9:01 UTC (open circles) and below 10 km at 7:09-7:12 UTC (solid circles) pressure altitudes on 23 October 1997. 
FERRY ET AL.: EFFECT OF AIRCRAFT ON AEROSOL ABUNDANCE IN THE UPPER TROPOSPHERE

FERRY ET AL.: EFFECT OF AIRCRAFT ON AEROSOL ABUNDANCE $\mathbb{N}$ THE UPPER TROPOSPHERE FERRY ET AL.: EFFECT OF AIRCRAFT ON AEROSOL ABUNDANCE $\mathbb{N}$ THE UPPER
TROPOSPHERE

T.P.Bui, G.V.Ferry, R.F.Pueschel, and A.W.Strawa, NASA Ames Research Center, MS 245-4, Moffett

Field, CA 94035-1000.

H.E.Fuelberg and J.R.Hannan, Florida State University, Tallahasse, FL 32306-4520.

S.D.Howard, Symtech Corporation, Arlinton, VA.

M.J.Mahoney, Jet Propulsion Laboratory, MS 246-101, California Institute of Technology, 4800 Oak Grove Drive,

Pasadena, CA $91109-8099$.

S.Verma, Science Systems and Applications, Inc., Lanham, MD 20706. 

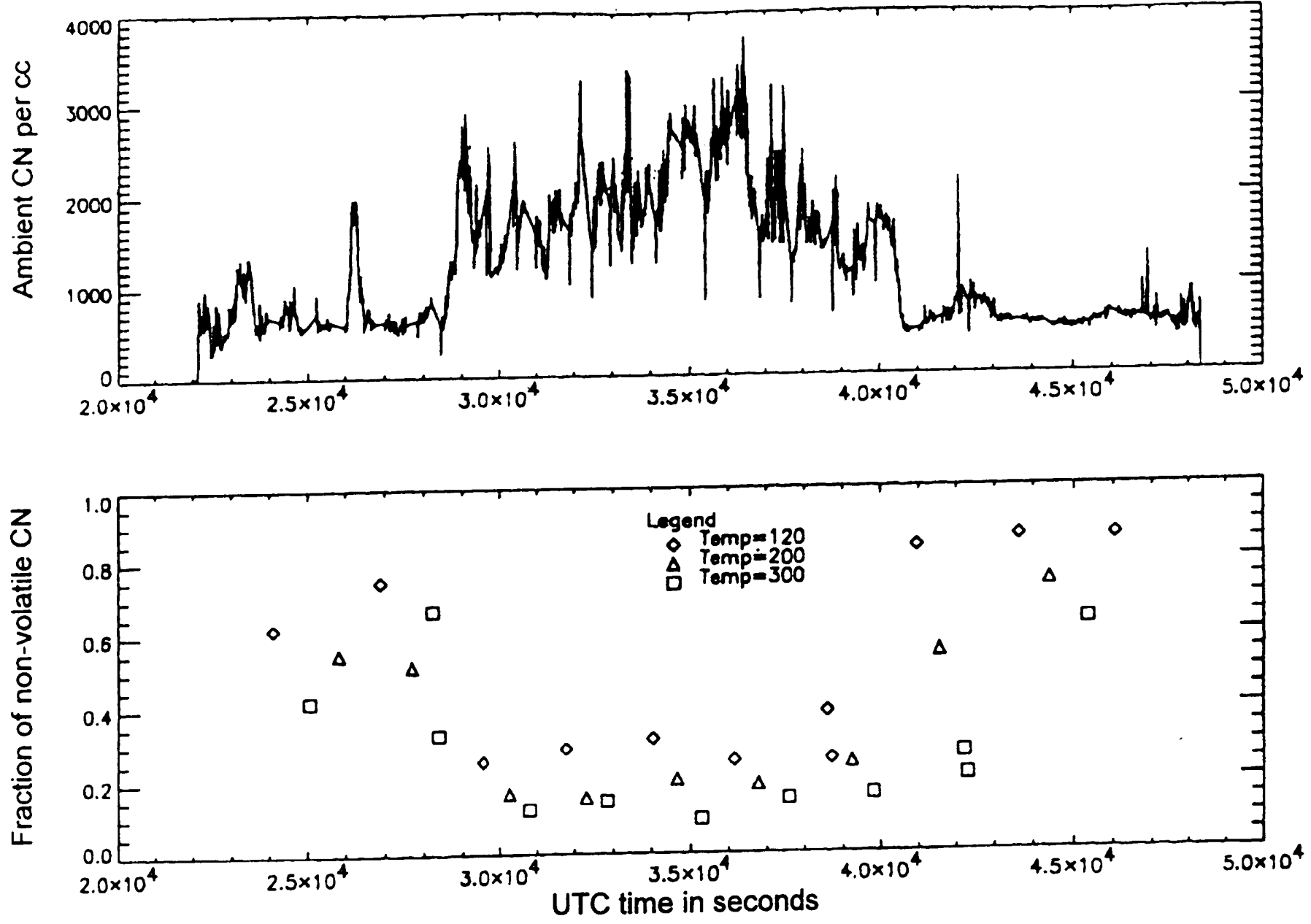

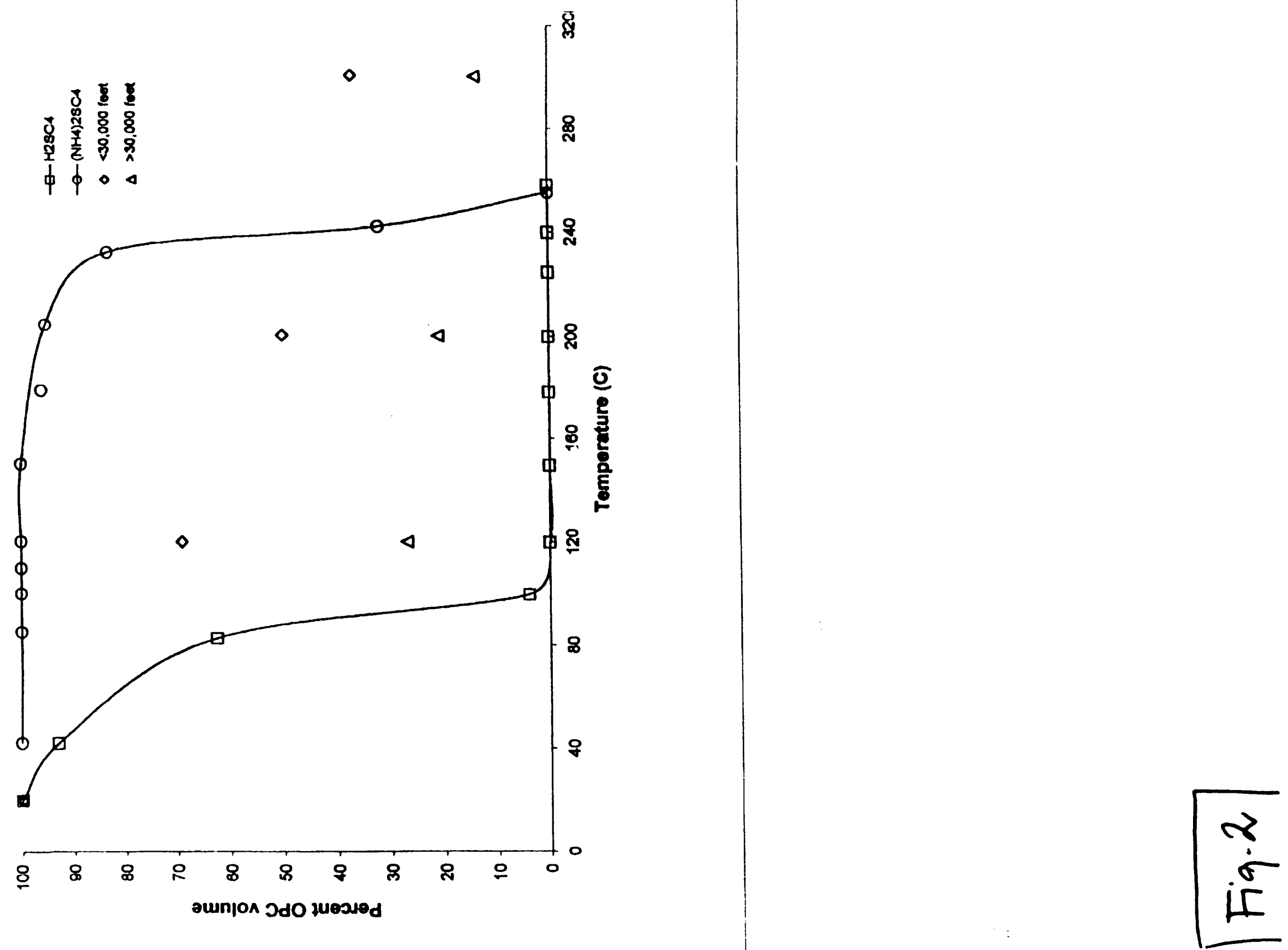

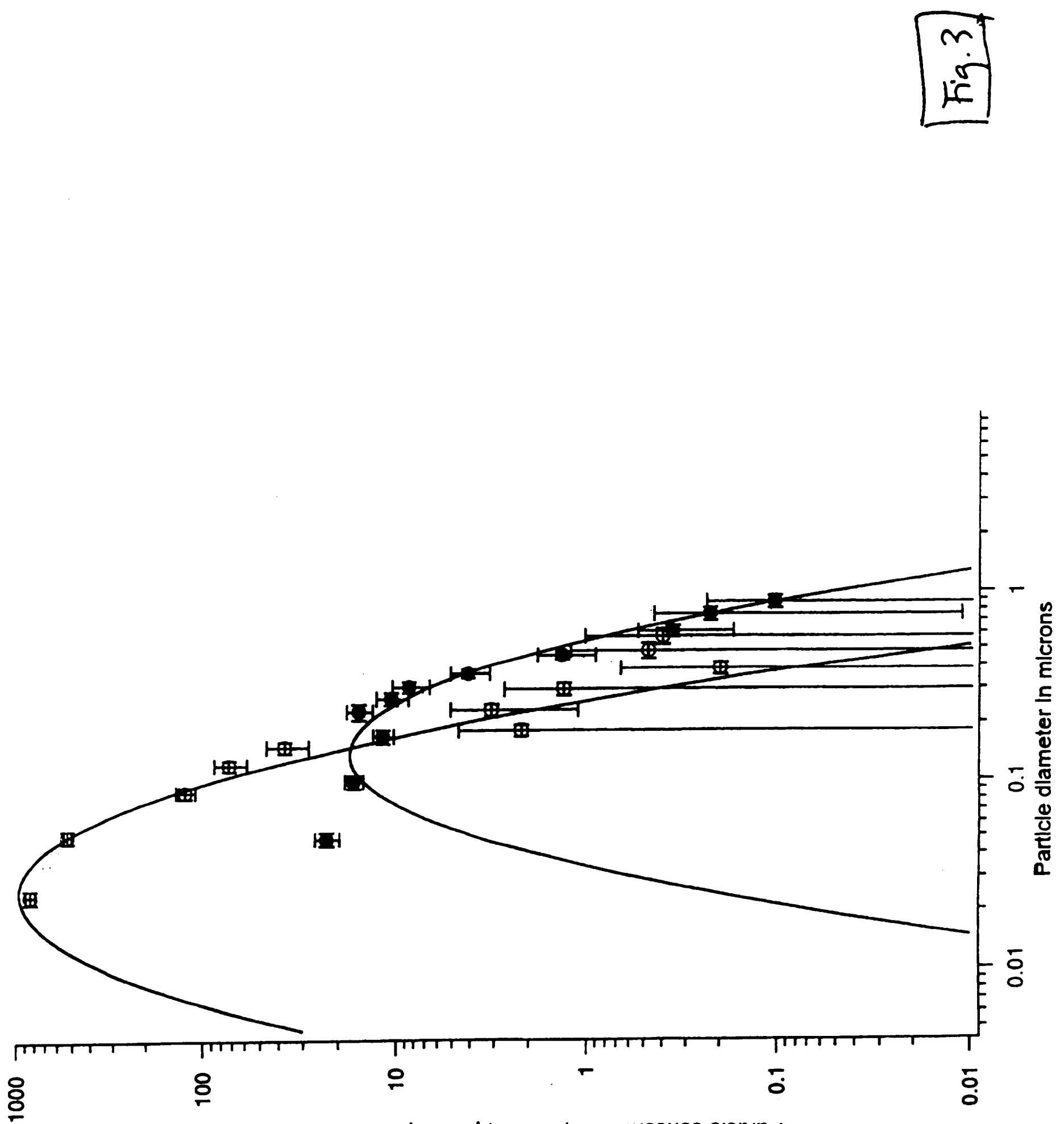

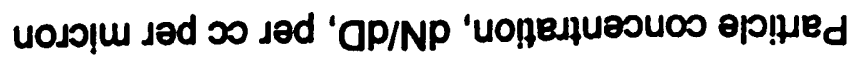

